\title{
Visualization requirements of engineers for risk assessment of embankment dams
}

\author{
Varun Kasireddy ${ }^{1 *}$, Semiha Ergan ${ }^{1}$, Burcu Akinci ${ }^{1}$ and Nur Sila Gulgec ${ }^{2}$
}

\begin{abstract}
Background: Aging infrastructure in the US has gained quite a bit of attention in the past decade. Being one type of a critical infrastructure, embankment dams in the US require significant investment to upgrade the deteriorated parts. Due to limited budgets, understanding the behavior of structures over time through risk assessment is essential to prioritize dams. During the risk assessment for embankment dams, engineers utilize current and historical data from the design, construction, and operation phases of these structures. The challenge is that during risk assessment, various engineers from different disciplines (e.g., geotechnical, hydraulics) come together, and how they would like to visualize the available datasets changes based on the discipline-specific analyses they need to perform. The objective of this research study is to understand the discipline-specific visualization needs of engineers from US Army Corps of Engineers (USACE) who are involved in risk assessment of embankment dams when they deal with large set of data accumulated since the inception of dams.
\end{abstract}

Methods: The requirements were identified through a three-phased research approach including interviews with engineers who are regularly involved in risk assessment processes, a card game and review of standards and published work on risk assessment of embankment dams.

Results: This paper provides the findings of research conducted with engineers coming from different disciplines within USACE. Findings comprise discipline-specific visualization requirements of engineers for viewing large datasets, containing static data (e.g. design information) and time-series data (e.g. piezometer data, monument measurements etc.), accumulated since the inception of dams.

Conclusions: The findings suggest that the visualization of the dam layout, components and geometry within 3D settings overlaid with sensor data (which could be queried based on engineers' discipline-specific needs) and data analytics results provide a better flexibility to engineers to understand the risk associated with potential failure modes.

Keywords: Mining; Built infrastructure; Human factors; Embankment dams; Visualization; 3D Modeling; Risk assessment

\section{Background}

Embankment dams, particularly, the aging ones are prone to failure with progressing time. Various types of failures, including internal erosion, sliding due to loading and overtopping, exist for an embankment dam. Many dams in the US have already received a "poor" rating as per the grade card released by American Society for Civil Engineers (ASCE) recently (ASCE 2013). Most importantly, these dams are an integral part of a prospering economy, and directly concern the lives of a large

\footnotetext{
*Correspondence: varunkasi@cmu.edu

'Department of Civil and Environmental Engineering, Carnegie Mellon

University, 5000 Forbes Ave., Pittsburgh, PA 15213, USA

Full list of author information is available at the end of the article
}

percentage of population living nearby. To repair and rehabilitate all of those dams are simply not possible due to budget constraints, and hence dams that require immediate remedial actions need to be identified and prioritized. One practical approach for this prioritization is through risk assessment, which includes the assessment of these dams periodically for the level of risk of failure and the magnitude of economic and life causalities associated with such a failure, and act accordingly.

Risk assessment process is an interdisciplinary process and involves engineers of various disciplines like Geotechnical Engineering (GT), Geology (GE), Hydraulic Engineering and Hydrology $(\mathrm{H} \& \mathrm{H})$, and Structural 
Engineering (SE). Also, risk assessment activities are typically carried out in different frequencies and granularities. Examples include daily monitoring, which is performed on the daily data collected on the dam to detect changes in readings overtime; periodic inspection (PI), which is conducted every five years in a detailed manner including historical data, and periodic assessment (PA), which is conducted every ten years with interdisciplinary parties. Currently, during these sessions, the multi-disciplinary team of engineers has access to different types of information, such as design, construction and operation information and accesses them through digital or hard copy documents. Collecting the required information and processing/analysing the document based information are resource and time intensive (Shaffner 2011).

Unique challenges that engineers face during risk assessment include (a) bringing a spatial context to the sensed data from piezometers, inclinometers, survey monuments and weirs, (b) understanding the behaviour of dams over time by correlating several parameters about dams (e.g., evaluating pool elevations with respect to piezometer readings, piezometer readings with respect to their station locations, piezometer tip elevations with respect to soil layers etc.). While data collection and processing efforts are preliminary data stages, it is the data visualization stage that plays a vital role in understanding the valuable information concealed inside the data. As data can be represented in different forms, and stored in multiple formats, it is important to understand which form is the most useful for the end users of the data, i.e., dam engineers in this case, to aid in the risk assessment process. For this purpose, it is necessary to identify the engineer's visualization requirements.

Engineers develop various artefacts to keep track of the correlations in mind, such as correlation plots, cross section layouts, piezometer locations on a plan view, lithology plans showing bore-hole locations and properties. Current tools and artefacts used by engineers do not enable them to perceive the data and correlations between them through views that can be generated flexibly based on how the engineers would like to look at the data. The artefacts are static and are not always capable of correlating the parameters at a glance (USACE 2012). Likewise, our initial interactions with engineers during a risk assessment session showed that the visualization requirements and corresponding modes of visualization vary as per the background of an engineer. For example, geotechnical engineers require to look at how different rock types are spatially distributed over the dam site and laboratory rock tests reflected as such. On the other hand, geologists intend to look at the same data in a layer-wise manner, and prefer to be able to turn on/off different rock-type layers within the same $2 \mathrm{D} / 3 \mathrm{D}$ visualization window. Consequently, this mandates the requirement of a flexible visualization paradigm to ensure effective and efficient perception and comprehension of the data.

Within the context of this paper, the authors provide the details of the findings on identification of discipline specific visualization requirements of engineers needed during risk assessment of embankment dams. The authors describe the challenges of present applications (see section The challenges of current applications), related background research (see section Background research), detail the three-pronged research methodology adopted in this study (see section Methods) and give details of the findings (see section Results and discussion). The identified visualization requirements in this domain are the main contributions of this paper, however the research methodology can be repeated to identify similar requirements in other decision domains. The paper concludes with recommendations and possible future directions.

\section{The challenges of current applications}

Current risk assessment procedure involves various engineering disciplines and several different types of documentation. Therefore, the effort is both, time and resource intensive as every engineer involved in the process needs to study the excessive documentation about the dam for weeks and repeat the same efforts in every risk assessment exercise for each dam. There are two main challenges that engineers deal with, as detailed below.

\section{Challenge 1: time and resource intensive effort to get a holistic understanding of the dam, its behaviour and its current condition}

Once the corresponding documents for a dam are collected, a 3-4 week time-frame is then allocated to do the assessment and get a complete view of the dam and its behaviour over time corresponding to the failure modes of that dam. Engineers need to study the documentation and also generate various artefacts to get a holistic view, and some of these artefacts generated for analysing a dam are illustrated in Figures 1, 2, 3 and 4. For instance, in order to understand if any piezometers have anomalies, they use time-series plots (as shown in Figure 1) where they plot the piezometer readings with respect to pool elevations. The interpretation of sensor readings depends on their location with respect to upstream or downstream of the dam, as well as in which soil layer the tip of each piezometer resides. Hence, in addition to the time series plots, they also look at plans that mark piezometer locations on the topography map as well as drawings that show cross sections of the dam with soil layers and piezometer tip elevations (Figures 2 and 3). Since several piezometers exist on a dam body, they generate the same plots for every station on the dam and for each piezometer. When there is large number of instruments on a dam, it becomes a challenge to relate all these artefacts to each other to 


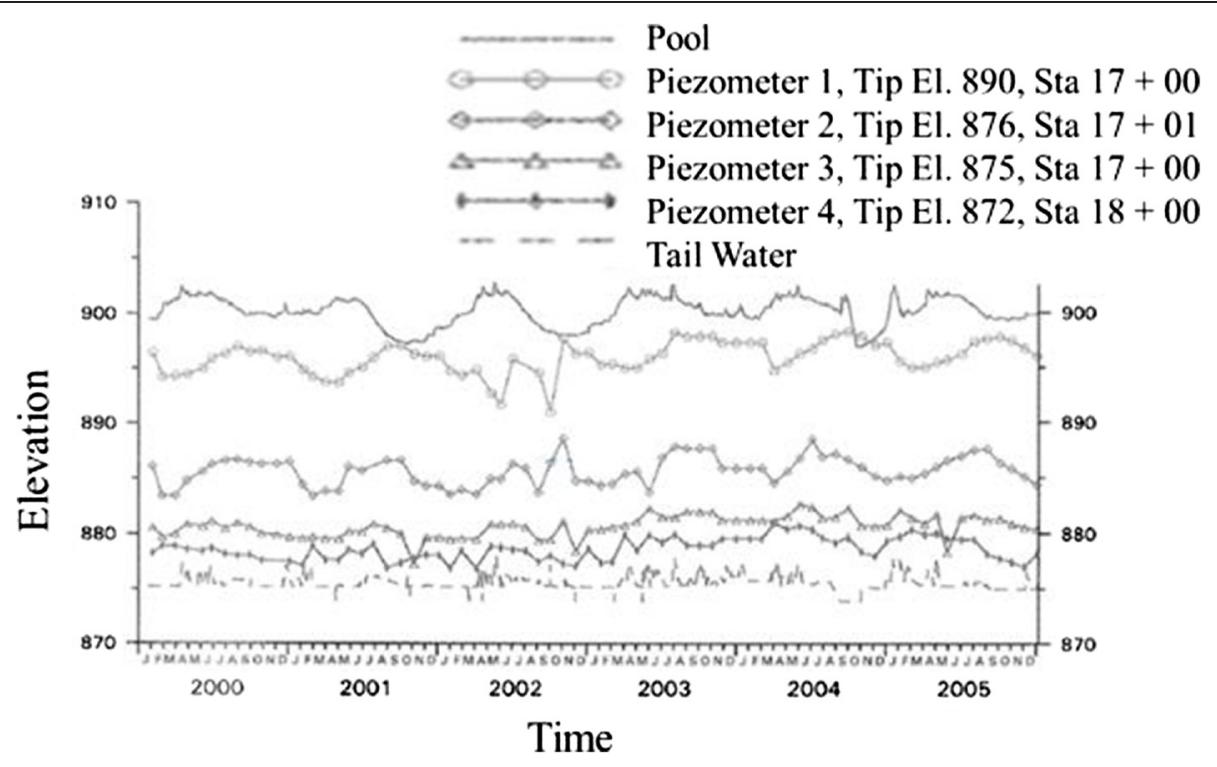

Figure $1 \mathrm{~A}$ time series plot showing the piezometer readings with respect to pool elevations.

understand the behaviour of the dam through data collected by the instruments. To help in that process, sometimes engineers also generate transparent physical mockups of the dams to keep track of the instrumentation (Figure 4).

\section{Challenge 2: bringing a spatial context to the sensed data from instrumentation}

Keeping every information and correlations between them in mind is impossible, given the fact that large number of instruments is used on a given dam and such instrumentation keeps providing data, at the minimum, on a daily basis. For example, a piezometer being read weekly from construction in 1944 through present (2013) would have over 3,500 data points. For a dam with 20 piezometers, it translates to over 70,000 piezometer data points. Meanwhile, a piezometer being read daily from construction in 1944 through present (2013) alone would have over 25,000 data points. Hence, bringing a spatial context to the instrumentation data and correlating them for both visualization and data analysis purposes is essential.

The first step towards such an approach is to identify what information should a shared repository contain. In addition to that, our observations with engineers suggested that engineers from different engineering disciplines want to look at the data from different views and this necessitates that requirements be identified based on engineering discipline. Table 1 is just an example of different visual requirements for looking at reservoir and tail water levels. It is evident that discipline specific

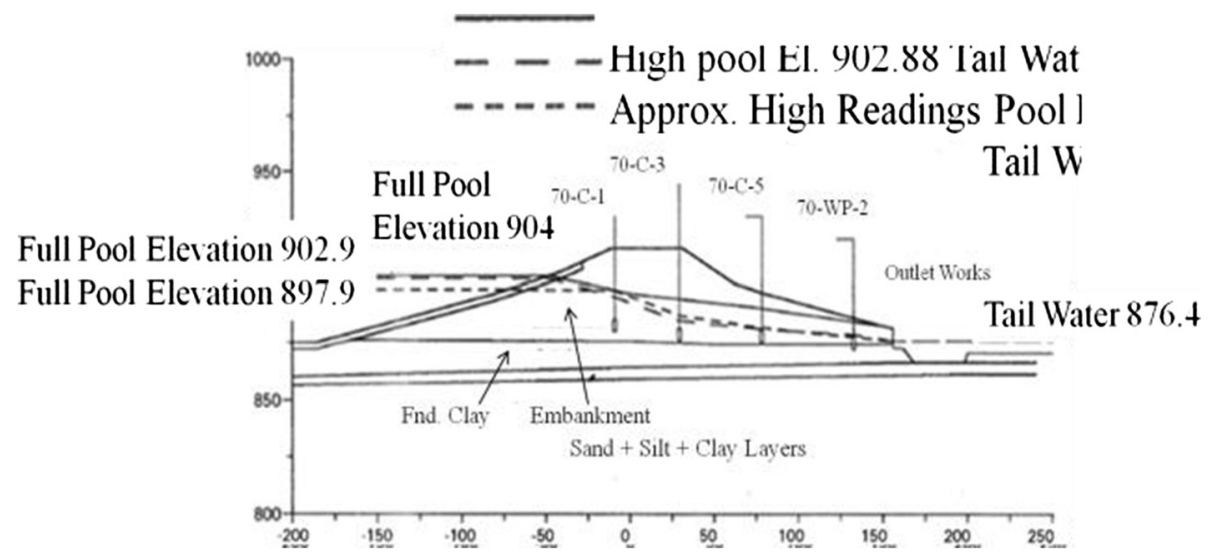

Figure 2 Cross section of a dam showing soil layers and pool elevations. 


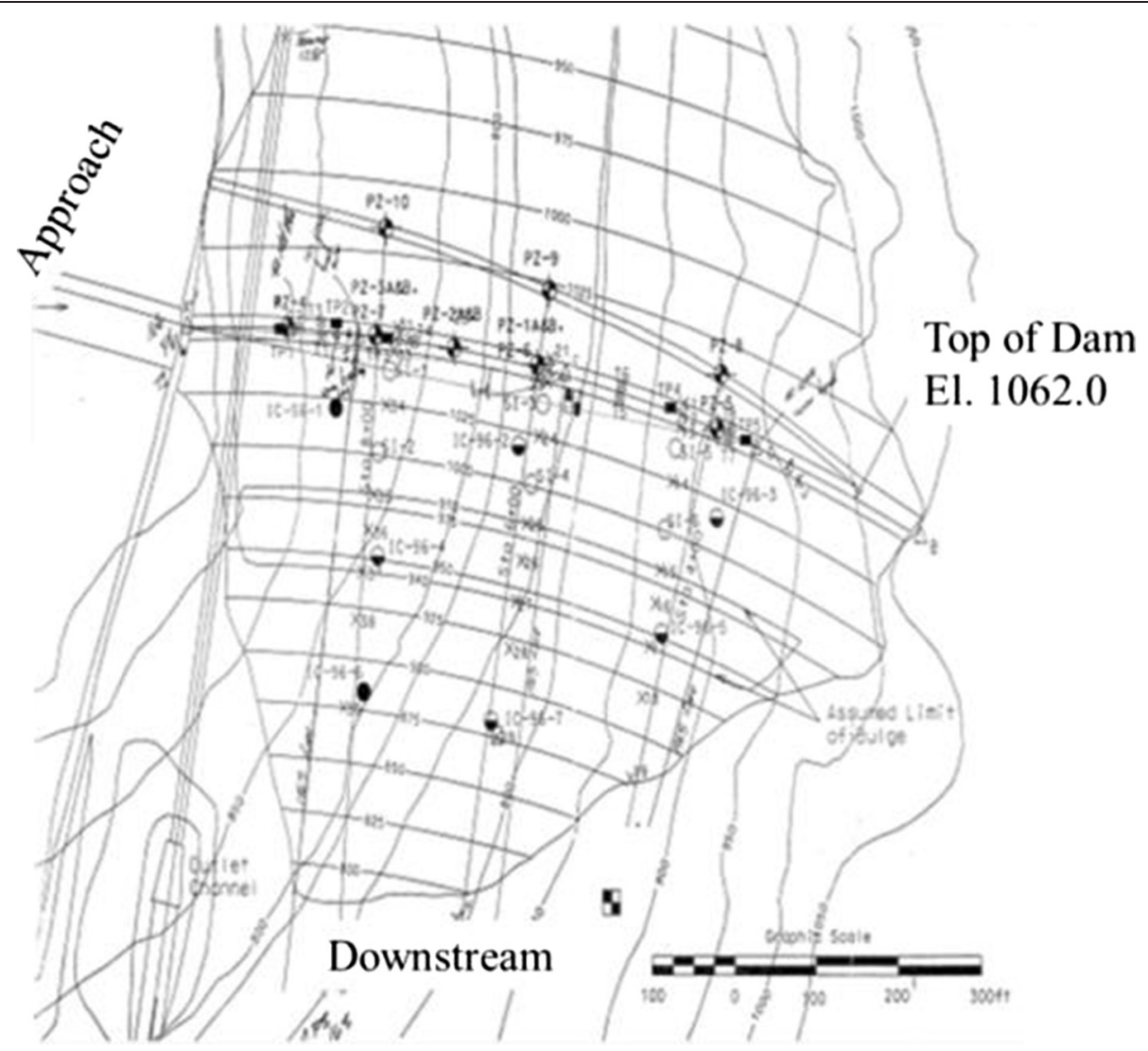

Figure 3 Plan view of piezometer locations.

requirements should be identified so that the developed repository can support the decisions of all disciplines involved in the risk assessment process. In summary, current applications to assess risk for embankment dams contain challenges of a) not capable of understanding whole behaviour of dam over time, b) visualizing instrumentation data with spatial context, c) lack of ways to

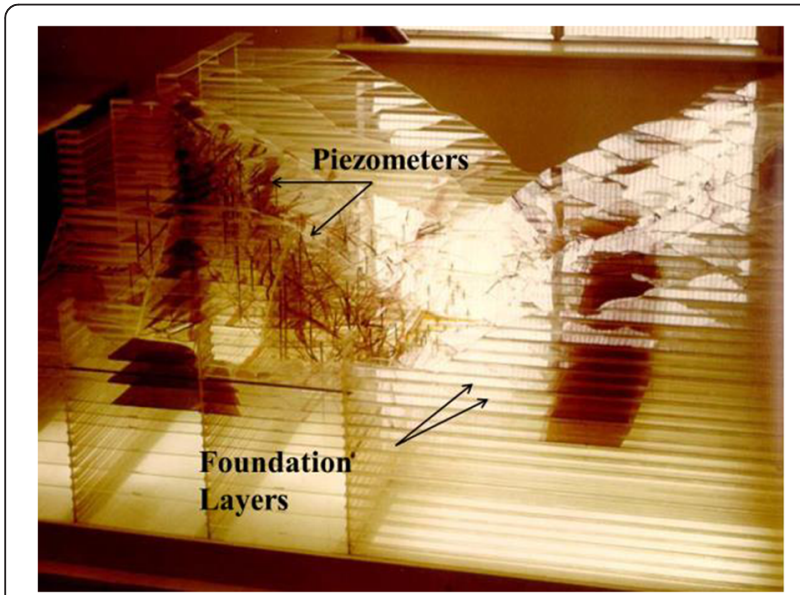

Figure 4 A transparent physical mock-up of a dam (Shaffner 2011). generate custom views that support how engineers would like to see the existing data for effective risk assessment. Therefore, this study targets the foundational work required to enable discipline specific visualization, and presents the discipline specific visualization requirements of risk assessors.

\section{Background research}

Several studies in the literature have been done in relation to usage of various forms of visualization to aid the dam risk assessment process. Harnessing different modes of

Table 1 An example collage of visualizing reservoir and tail water levels based on engineering disciplines

\begin{tabular}{ll}
\hline Discipline & Reservoir and tail water level \\
\hline Geotechnical Engineers & $\begin{array}{l}\text { Would like to see the top } 10 \text { events that have } \\
\text { occurred and study the differential rating \& } \\
\text { performance for these events. } \\
\text { Would like to graphically see water levels per } \\
\text { Geologists }\end{array}$ \\
Hydrologists & $\begin{array}{l}\text { Would like to visualize inflow-volume-duration- } \\
\text { frequency curves (1-7 day computed probabilities). } \\
\text { Structural Engineers }\end{array}$ \\
& $\begin{array}{l}\text { Would like to see hydrologic loading data for } \\
\text { coincident pools for seismic Probable } \\
\text { Mass Function's. }\end{array}$ \\
\hline
\end{tabular}


visualization, i.e., 3D and 4D, to present different types of information from disparate sources enhances the ability to absorb the content, as well as the ease of its access, when required (Pantea et al. 2011). Some of the studies might be grouped such as multi-dimensional visualization, Geographic Information Systems (GIS) and real-time monitoring applications.

Multi-dimensional visualization techniques, which include 3-D and 4-D analyses, enable better understanding, access and presentation of the integrated information from different type of sources (Cross et al. 2005). 3-D modelling techniques have been widely used to display volumetric characteristics of a given structure, such as surface mapping, surface hydrology, and groundwater levels (Glynn et al. 2011); the piezometer and water levels (Spencer et al. 2010) and water surface variations during flood (Lai et al. 2011). In addition, there are various studies about the modelling of the geometric surfaces and 3D layers that carry the lithological and hydraulic level characteristics (Dominguez-Acosta et al. 2004) and associated functionalities, such as saving, rotation, zoom, cut and slice (Xi-juan et al. 2010). Another multi-dimensional technique is 4-D modelling that gives insight for engineers about the behaviour across time. These studies help to analyse the current conditions and guess the possible future actions by displaying time variant behaviours (Brindley et al. 2006).

Geographic Information Systems (GIS) have been widely used in approaches to remedy information access about dams. In these studies, different data or their consequences can be displayed over the geologic maps. Various applications include (a) modelling of dam performances, such as levee performance and the failure modes and their visualization (Serre et al. 2008), (b) flood damage estimations (Qi and Altinakar 2011), and (c) visualization of data required for cut-off wall construction (Rosen et al. 2011). GIS have been the primary data visualization medium in the dam safety studies and used to integrate various geodatabases to enable information exchange between such systems (Shumilov and Breunig 2000). Apart from 2D- 3D visualization of behaviour of dam and site features and characteristics over time, engineers also prefer to easily access past construction photos and reports, in order to understand what features of the dam have changed over different phases of its life cycle. A very good example is the newly renovated Wolf Creek Dam in the US, where the instrumentation and construction data have been evaluated in relation to a geo-database and a 3D model of the dam. This integrated model supports engineers to analyse and predict the possible consequences of seepage and stability problems (Spencer et al. 2010).

Several researchers have also worked on fully automated systems and web-based visualization techniques to facilitate quick feedback and information dissemination during multi-disciplinary meetings with participants from disparate locations (Lemke et al. 2011). Continuously collected geotechnical, hydraulic and historical data assist engineers to build decision support system to analyse, supervise and forecast risk. For example, a web-based decision support system, which enables visualization of risk levels with colours, has been implemented to support estimating the flood failure risk of dikes (Maccabiani and Knoeff 2008).

Although the previous studies are helpful to visualize and query information about dams in general and ease the decision making process, there is a lack of research studies in the domain that look at the dam risk assessment process and focus on developing an integrated shared knowledge repository for risk assessors. These studies did not focus on developing a holistic understanding of the ways engineers would like to look at the data, given their engineering discipline, and developing visual forms to enable those. The study presented in this paper focuses on characterization of such visualization needs to better serve engineers during their decision making processes while assessing risk levels of dams.

\section{Methods}

The main objective of this study is to understand the requirements of the engineers with regard to their preferences in visualizing information while performing embankment dam risk assessment activities for a dominant failure mode. This paper provides findings in relation to internal erosion. Internal erosion, in particular, is complex to understand, and can even be triggered by normal day-to-day operations without a high intensity event like frequent high pool elevations. Internal erosion is also a major cause of failure of embankment dams (Blackett 2013), and hence was the reason to focus on internal erosion in this study. Previous literature on requirements elicitation (Wiegers 1999); Gould and Lewis (1985) suggests that the most productive approach to accumulate and analyze requirements for a specific task is to determine use cases and build prototypes with varying levels of details while utilizing user feedback at each stage of the prototype development process. The research team used a similar approach that incorporated a multi-phased requirement elicitation and case analysis to interact with engineers and document their visualization requirements during risk assessment process.

A three phased approach was used in this study to identify and validate the visualization requirements of engineers drawn from different disciplines. These phases are described in details in subsequent sections.

\section{Phase 1: requirements elicitation through systems investigation and interviews}

In this phase, the research team conducted face-to-face unstructured interviews with engineers involved in risk 
Table 2 Overview of participants of the study

\begin{tabular}{lccll}
\hline Phase & $\begin{array}{l}\text { Number of } \\
\text { participants }\end{array}$ & $\begin{array}{l}\text { Years of } \\
\text { experience }\end{array}$ & $\begin{array}{l}\text { Mean and standard } \\
\text { deviation }\end{array}$ & Discipline (s)* \\
\hline I & 7 & $10-32$ & $\mu=19.1 ; \sigma=9.6$ & $\begin{array}{l}\text { H\&H, GT, SE, } \\
\text { GE, CE }\end{array}$ \\
$\|$ & 5 & $13-37$ & $\mu=27.6 ; \sigma=9.7$ & $\begin{array}{l}\text { GT, H\&H, GE, } \\
\text { CNSTR, SE }\end{array}$ \\
III & 2 & $4-16$ & $\mu=10.0 ; \sigma=8.5$ & H\&H, CE \\
\hline
\end{tabular}

*H\&H: Hydraulic Engineering and Hydrology; SE: Structural Engineering; GE: Geology; GT: Geotechnical Engineering; CE: Civil Engineering; CNSTR: Construction Engineering.

assessment processes, and investigated the information systems used by the engineers to understand different views/figures currently generated with these systems. The larger goal of this phase is to compile a preliminary list of visualization requirements which would constitute an initial list of use-cases for a more-structured elicitation and validation of requirements. 15 engineers from different disciplines, as detailed in Table 2, participated in this study. Majority of these engineers were experienced engineers who have been involved in risk assessment processes for several embankment dams. Several systems are currently used by engineers to store, access, and visualize the collected sensor data. They gave integrated plotting, reporting and GIS-linking capabilities, based on predetermined templates. Various computational tools are used during risk assessments, including geographic information systems, geotechnical integration systems, 3D modelling systems and data viewers. During the study, these systems have been evaluated as part of the preliminary analysis so that the preliminary list of visualization requirements could be enumerated and that they could be communicated and discussed during the Phase I interviews with the engineers.

The primary focus of the interviews during Phase 1 was to capture discipline specific visualization requirements without delving too much into the process of extracting only those requirements which are relevant to the particular failure mode being assessed in this study. These preliminary findings were also useful to determine how engineers would like to visualize different dam features, and also to remove the ambiguity, if any, in the meaning of the terms from the perspectives of each engineering discipline.

\section{Phase 2: requirements elicitation through a card game, examination of standards/guidelines and case documentation}

Unlike the previous phase, wherein the requirements were collected in a generic sense, in this phase, the focus was particularly on assessment of internal erosion problems. In this regard, a card game was designed to expand the initial findings of the Phase I. Additionally, the team investigated standards and publications related to internal erosion assessment; and other risk assessment documentation available for three selected dams. The main strategy here is to corroborate the visualization requirements based on the analysis of multiple sources of information, i.e., through triangulation. Triangulation ensures the generality of the findings.

To approach capturing the discipline specific visualization requirements of engineers, a card game was designed to be used with accompanying scenarios. The card game included pile-of cards, and each card represented an information item that an engineer might be interested in knowing to understand the behaviour of a dam. Piles included several categories such as information about instrumentation, embankment features, historic reports, field tests, and drawings. Among each pile of cards, blank note cards were placed to accommodate the situation in which a participant asked for information that was not already represented in the pile of cards. A scenario represented a risk assessment case in a given dam setting where all the requested information by the participants assumed to be available. For every card (i.e., an information item) asked by a participant, participants were asked to define how they would like to visualize that information.

As part of the triangulation efforts, the research team examined various engineering guidelines/manuals like engineering manuals (EM), engineering regulations (ER). In addition, for three selected embankment dams, the research team examined the plots and visualization approaches used to depict or highlight identified facts about the dams in previous risk assessment reports.

\section{Phase 3: requirements validation through prototype development and face validation}

The main tasks carried out in this phase to validate the requirements identified in the above two phases included development of a functional prototype integrating all visualization requirements, and taking user feedback regularly through showing each identified and implemented view. The prototype was developed using an object oriented language and enabling renderings of rich 2D-3D graphics. With this prototype, it was possible to do face validation with the users in terms of pinpointing any discrepancies between what the research team interpreted versus what the users actually asked for.

For the face validation step, engineers provided their feedback on the identified visualization requirements to define whether the captured requirements represented what they described earlier and if they have any additional requirements to include. Regarding the feedback on the functional prototype, only two engineers participated on the evaluation a weekly basis for six months. The authors intend to perform functional evaluation of the prototype using a larger pool of engineers as the 
next step when they have access to a real Periodic Assessment and data about the dam being assessed.

\section{Results and discussion}

The findings are presented in terms of what has been identified as visualization requirements through the requirements elicitation approaches and then how the findings were implemented in the functional prototype.

\section{Identified visualization requirements}

The research team identified a total of 42 unique visualization requirements based on the research methodology outlined in the previous section. They have been tabulated in Additional file 1: Table S1 based on the engineering disciplines and the overarching categories of visualization. Observations from Additional file 1: Table S1 reveal that some of these discipline-specific requirements overlap with those of other disciplines, and the details of the same are discussed in the subsequent paragraphs. For the convenience of the reader, the authors have highlighted the overlapping requirements across different disciplines in bold font in Additional file 1: Table S1. As a whole, Additional file 1: Table S1 gives an idea of how visualization requirements vary with engineers from different backgrounds for the case of internal erosion risk assessment.

The distribution of the findings with respect to the engineering disciplines is not equally distributed. We can clearly understand from Additional file 1: Table S1 that $76 \%$ of the total unique visualization requirements were provided by geotechnical engineers and $38 \%$ of the requirements were provided by geologists, with overlapping requirements between groups. They were followed by Hydraulic engineers/Hydrologists (H\&H group), who contributed to $17 \%$ of the total requirements. Similar in scale to the $\mathrm{H} \& \mathrm{H}$ group, structural engineers contributed only $14 \%$ of the total. The reason for having a wider set of requirements stated by geotechnical engineers and geologists is due to the scope of the problem being internal erosion, which falls more to the domain of geotechnical engineers. Also, since the scope of this study was limited to embankment dams in which structural features are minimal in comparison to other dam types such as the concrete dams, having a less number of requirements defined by structural engineers is expected.

When Additional file 1: Table S1 is analysed in terms of commonalities of visualization requirements based on engineering disciplines, it was observed that only $7 \%$ of the total 42 requirements such as geometrical information about dams; pre-existing structures; and reservoir pool and tail water elevations; were of interest to the engineers to look at collectively from all disciplines. There was a consensus among engineers regardless of their disciplines regarding certain visualization requirements. For example, all engineers preferred to have site plans for pre-existing features, which are important to know about for internal erosion assessment, around the dam site in 2D views. Similarly, the opinion was unanimous as far as the representation of dam geometry and information related to it in a $3 \mathrm{D}$ view. They also would like to have additional tools to be able to export different cross sections and plan views, and to turn on and off different layers (e.g., instrumentation, zoning, soil layers, pre-existing site plan, etc.). All disciplines also underscored the importance of visualizing the zoning within the dam (e.g., cross-hatching, colour, etc.) as well as the reservoir and tail water information. Here, all the engineers prefer to access the raw reservoir pool and tail water elevations and look at the related plots in a single view. In the same context, engineers would also like to be able to visualize water levels and flows over time (i.e., a 4D simulation of the water level on 3D dam geometry). In addition to these, the research team studied and identified that some of the requirements i.e., instrumentation information and readings provided within 3D settings and geotechnical and geologic information provided in plan views were common to at least three engineering disciplines.

Though there are overlaps in the visualization requirements among engineer disciplines, the percentage of overlap varies with the discipline specific visualization requirements. For instance, from Additional file 1: Table S1, it is evident that most of the $3 \mathrm{D}$ visualization requirements of geotechnical engineers overlapped with the requirements of the engineers from other disciplines. The overlapped features include turning on/off various layers of the information on the 3D model as well as visualization of instrumentation information (e.g., location, tip elevation, etc.) and instrumentation readings within the 3D settings. In contrast to that, the requirements of geologists do not have many overlaps with engineers from other disciplines.

Specific to the H\&H group, hydraulic engineers were interested in the features enabling the visualization of regional rainfall inundation map, Possible Maximum Flood regional map, Hydro Meteorological Report-51 i.e. a probable maximum precipitation document, and the $3 \mathrm{D}$ view of the dam geometry. Furthermore, they also expressed interest in accessing tail water, pool elevation and reservoir inflow characteristics in a tabular form. Besides that, they also wanted to look at the hydrologic loading data for coincident pools for seismic PMFs, hydrologic loading data for flood events, inflow-volumeduration-frequency curve [1-7] day computed probability, pool-frequency, and pool-duration curves.

Incidentally, the visualization requirements of the structural engineers have a good overlap with those of the 
$\mathrm{H} \& \mathrm{H}$ group as far as the $\mathrm{H} \& \mathrm{H}$ tabular data is concerned. They have additional requirements for $3 \mathrm{D}$ visualization of the dam instrumentation and the site plan. On the other hand, the interests of civil engineers lie in the availability of instrumentation data - in the form of tables, and 3D geometry of the dam.

\section{Implementation of visualization requirements in the functional prototype}

The prototype was developed in an iterative and a participative manner, in which the opinion and feedback of the end users regarding the functionalities incorporated in the prototype, visual requirements implemented, and usability aspects, were regularly taken to customize existing features and also add new features if necessary. Initially, a view for accessing and displaying instrumentation meta-data was implemented along with a 2D data viewer for static $2 \mathrm{D}$ plots (i.e., requirements 7, 9, 15 and 16 in Additional file 1: Table S1). A 3D model viewer was built in to the model and integrated with several required data to display contextual information about dam features and instrumentation data were added (i.e., requirements 25, 26, 29, 30, 33 in Additional file 1: Table S1) (Figure 5). In the next phase, querying capabilities for instrumentation data were incorporated (i.e., requirement 34 in
Additional file 1: Table S1). 2D data viewer was augmented with a dynamic time slider to visualize variation of readings over time (i.e. requirement 8 in Additional file 1: Table S1), based on the feedback of engineers. In the following phases, views for bore-hole test results (i.e., requirements 18, 20, 37, 38 in Additional file 1: Table S1), document/ photo access panels and image display capabilities were added to the prototype (i.e., requirements 1-6 and 10-14 in Additional file 1: Table S1).

Discussing all the features implemented in the prototype is out of scope of this publication; simply due to their sheer number and the space restrictions. However, some of them are detailed below.

\section{Implementation for visualization of piezometer meta-data and time-series readings}

In relation to instrumentation data visualization, piezometers were the commonly referred instrument type to know about for internal erosion assessment. Engineers wanted to select different piezometric zones of influence within the 3D dam body and select the desired piezometers within them to examine their meta information. Metadata and additional information to be specified for each piezometer included tabular and plotted piezometer data over time with respect to pool elevations,

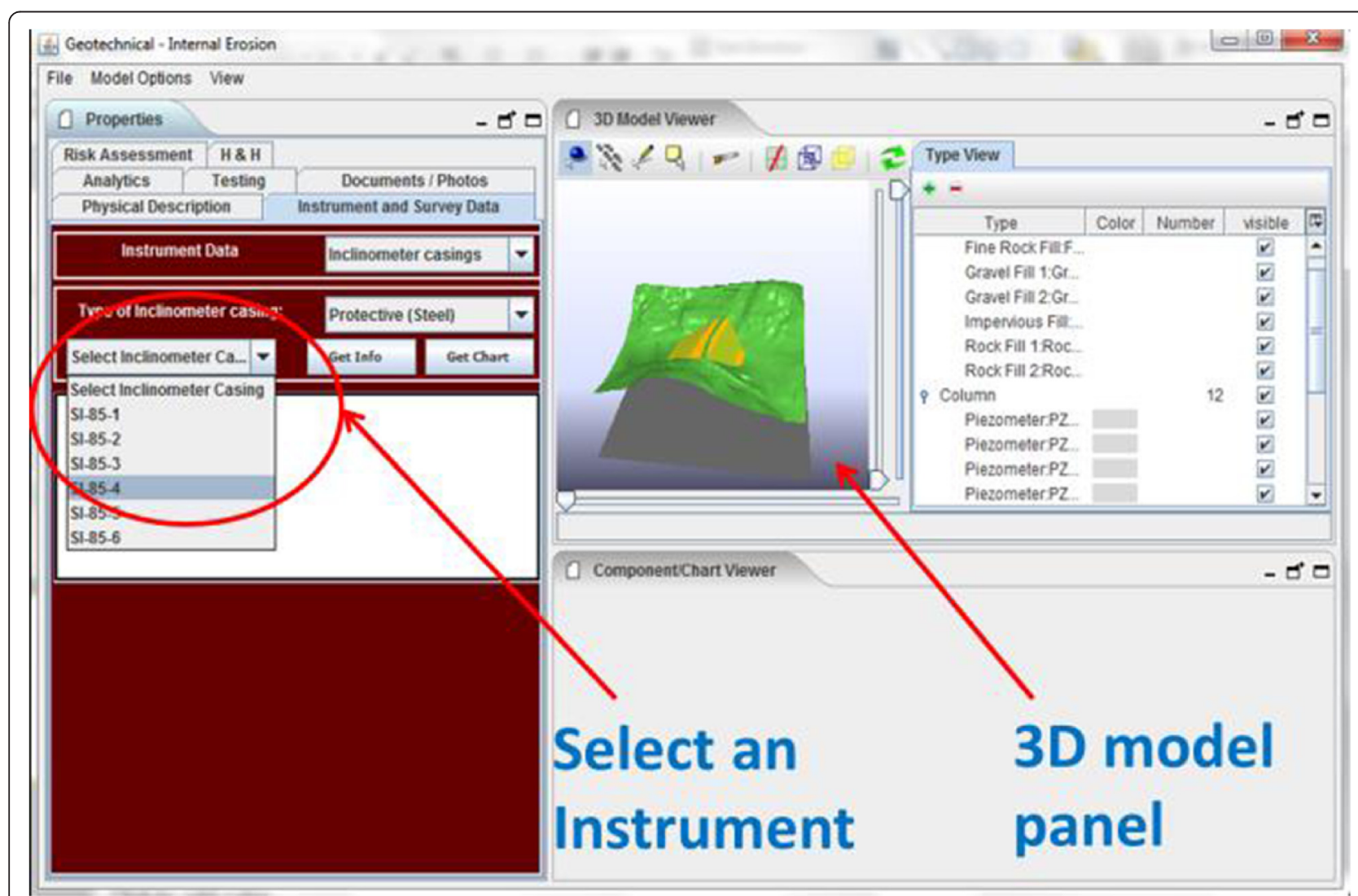

Figure 5 A snapshot showing 3D model panel. 
instrument location and tip elevation with respect to soil layers and stations in the dam, as well as piezometer influence zone in 3D phreatic surface (i.e., requirements 8, 9, 33 in Additional file 1: Table S1). In addition to this, engineers would like to compare different piezometers using the querying functionality and plotting their readings over time along with the pool elevation variation using the time slider; and in the form of time series data were implemented- as shown in Figure 6. In the initial implementation, only the time series corresponding to the piezometers were plotted. However, the engineers indicated that it would be useful to them to understand any anomalies in piezometers if their readings were plotted alongside the reservoir pool levels. Thereafter, this feature was augmented to show even these details, on an asdesired basis.

\section{Implementation for visualization of testing data such as boring logs and rock tests}

Within testing data, "boring logs" is one of the frequently used words in the interviews with most of the geotechnical engineers and geologists (i.e., requirements 20 and 38 in Additional file 1: Table S1). Important features implemented, concerning boring log information, are meta-data display of any selected bore hole inside a data panel; and display of different soil strata within each

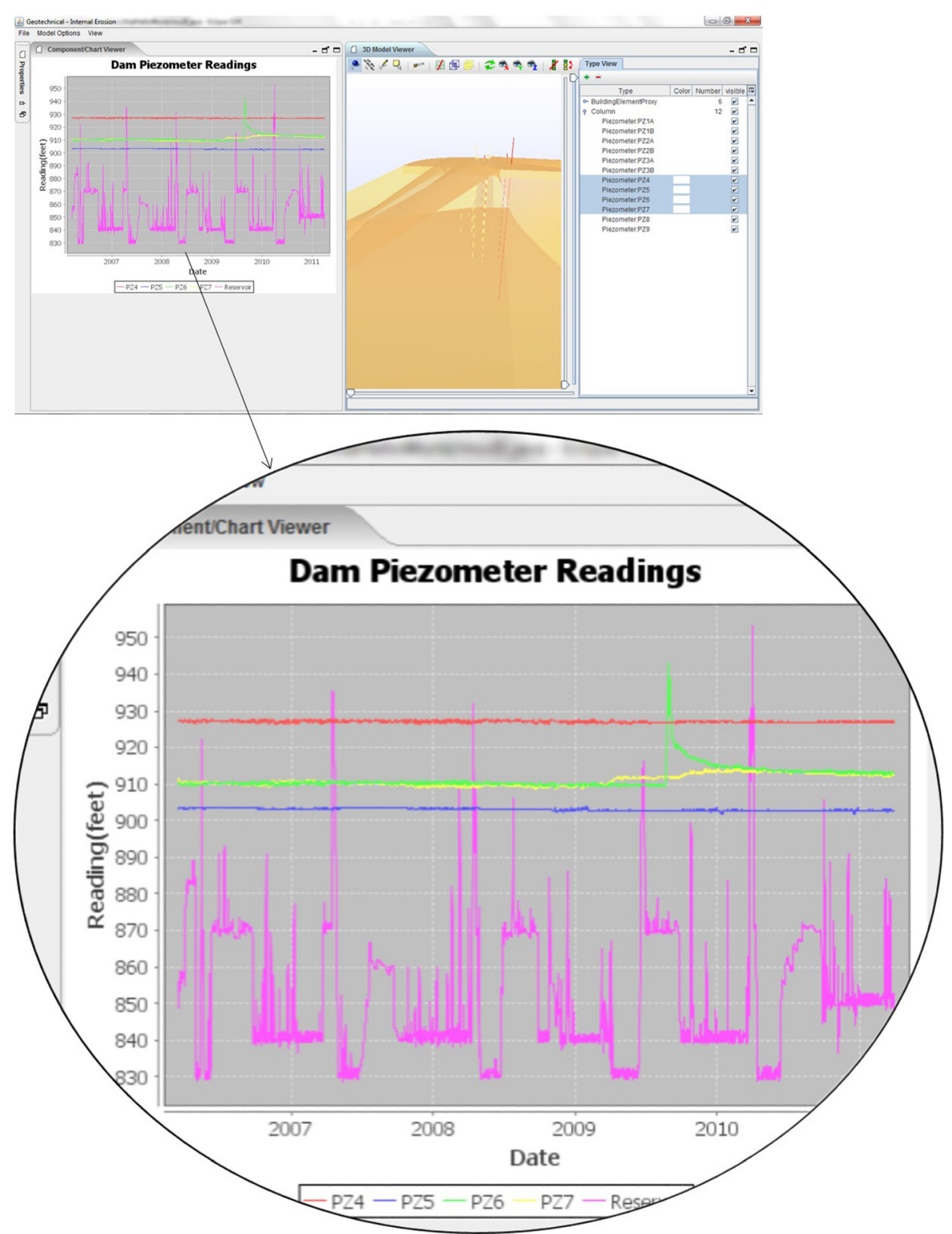

Figure 6 A snapshot showing a time series of selected piezometers. 


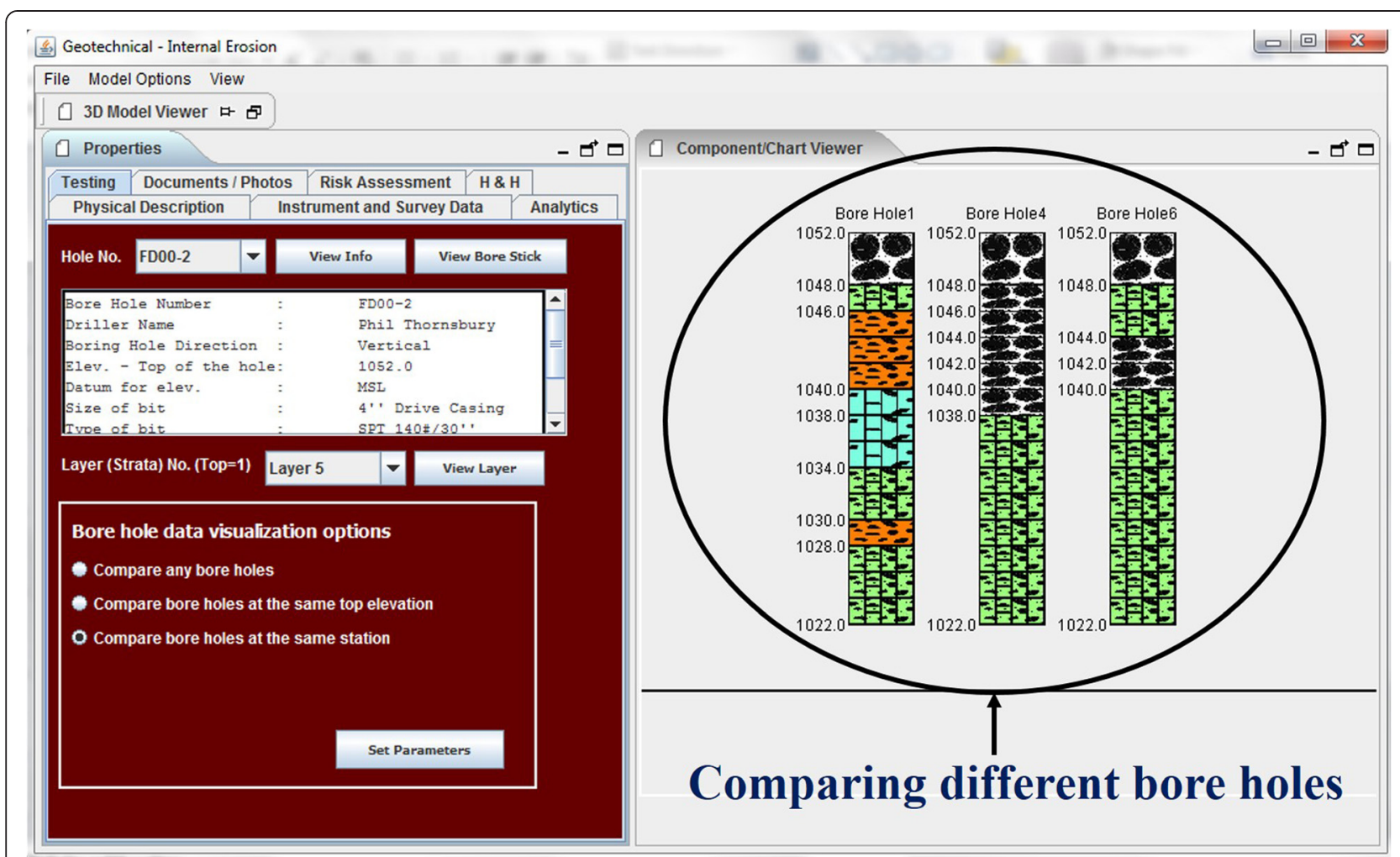

Figure 7 A snapshot showing that different bore holes can be compared (we can see different strata layers of each bore hole in this figure).

boring log. As engineers also showed tremendous interest in the ability to query for different bore holes based on a certain criteria, advanced query docking frame has been implemented for customized comparison, and here, users are able to put different boreholes side-by-side and view their strata properties, and meta information and other related information (as shown in Figure 7). During validation of the functional prototype, after examining the implementation, the engineers mentioned their preference for the texture mapping of different soil strata with the conventional plot legends that they currently use in existing documentation. They believed such a feature would help them correlate strata, its properties and behaviour quickly, as they are already used to these conventions during their daily work routines.

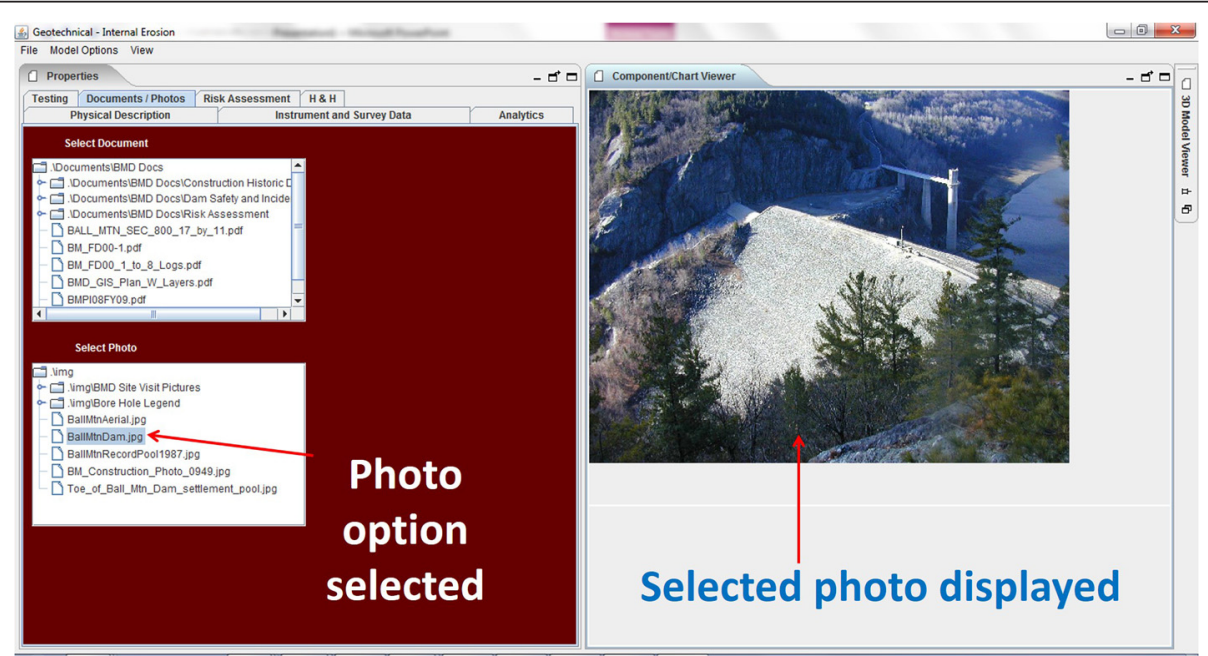

Figure $8 \mathrm{~A}$ snapshot is showing various documents and photos can be stored and accessed from the integrated prototype. 


\section{Implementation for visualization of documentation and construction history photos}

Most of the dams have been constructed many years ago and they have lot of paper documentation concerning its construction history, repairs, site instrumentation, standards, etc. With time, it becomes very difficult to retrieve particular old documents, say, if needed for a risk assessment process or even for the perusal of the project engineers. Hence, engineers wanted an internal document indexing system within the prototype to drag and drop digitized files and photos and to be able to retrieve these indexed files quickly within the same interface, whenever needed. The implementation of this feature is shown in Figure 8, wherein a user selected a photo from the file index panel, and it is being displayed in the adjacent docking panel.

\section{Conclusions}

Visualization empowers engineers to conveniently visualize, integrate and accurately interpret the data from disparate sources. For internal erosion risk assessment in embankment dams, engineers from several disciplines require dam information to be viewed from different perspectives. This study provides the findings of visualization requirements of engineers involved in risk assessment processes while looking at historical dam information.

While the engineers would like to be able to use the current methodologies they are using to visualize static data related to embankment dams, they desire for an advanced $3 \mathrm{D}$ visualization paradigm that allows the end users to at least import different cross sections and plan views; turn on and off different information layers concerning instrumentation and other site plans; and simultaneous comparison through querying and visualization of multiple boring logs, piezometers, and monuments.

The findings from this study suggest that engineers would like to visualize the dam layout, components and geometry within 3D settings overlaid with sensor data, and querying capabilities in order to get a better flexibility to understand the risk associated with potential failure modes. The authors believe that, armed with this flexibility, engineers can be more effective and efficient during risk assessment sessions, and can contribute to better dam maintenance decisions. However, the validation of effectiveness and efficiency for decision making is a required next step. Validation will be more effective when performed during an actual periodic assessment of a dam. The main contributions of this paper comprise the visualization requirements in the domain of dams, which has not been attempted before. However, the same research methodology can be utilized to extract requirements in other decision domains.

Future work can include putting efforts to quantify the value of using visualization tools, discussed in the study with engineers, through scenarios from a specific dam for assessment of internal erosion during a real PA exercise. Among the instruments mainly used in the data collection tasks at the dam location, the research team focused mainly on the piezometers in the risk assessment process for the current study. In the future, other available instrumentation and their readings could be investigated to understand internal erosion risk and risk due to other failure modes in a holistic manner.

\section{Additional file}

Additional file 1: Table S1. Identified Visualization Requirements Visualization Mode wise. Note - 1) Only the requirements which are repeating i.e. overlapping over two or more disciplines' requirements are marked in bold text. 2) The first instance of occurrence of each requirement is numbered, and the repeating instances are listed in bullet format.

Competing interests

The authors declare that they have no competing interests.

\section{Authors' contributions}

VK contributed to conception and design; analysis and interpretation; data collection; critical revision of the article; statistical analysis; and takes the overall responsibility of the paper. SE participated in conception and design; analysis and interpretation; data collection; writing the article; critical revision of the article; statistical analysis; and obtained funding for the project. BA participated in conception and design; critical revision of the article; and obtained funding for the project. NSG participated in analysis and interpretation: data collection; writing the article; critical revision of the article; and statistical analysis. All authors read and approved the final manuscript.

\section{Acknowledgements}

The research presented in this paper is supported by USACE grant. The authors would like to acknowledge the support of Chris Kelly, Meghann Wygonik and other engineers from USACE who participated in this research at various stages. Also, we developed the prototype using the research version of java toolbox provided by IFC Tools Project (Tulke et al. 2013).

\section{Author details}

${ }^{1}$ Department of Civil and Environmental Engineering, Carnegie Mellon University, 5000 Forbes Ave., Pittsburgh, PA 15213, USA. ²Department of Civil and Environmental Engineering, Lehigh University, 13 East Packer Avenue, Bethlehem, PA 18015-3176, USA.

Received: 31 July 2014 Accepted: 20 November 2014

Published online: 16 January 2015

\section{References}

American Society of Civil Engineers (2013). America's Infrastructure Report card. On-line: http://www.infrastructurereportcard.org. Accessed: 27 Jan 2014.

Blackett, F (2013). Potential Failure Modes for Piping and Internal Erosion. On-line: http://www.oregon.gov/owrd/SW/docs/dam_safety/M6_Blackett_Internal_ Erosion.pdf. Accessed: 29 Jan 2014

Brindley, TL, Tarantino, JJ, Locke, AL, \& Dollins, DW (2006). Utilization of 4-Dimensional Data Visualization Modeling to Evaluate Burial Ground Contaminants at the Paducah Gaseous Diffusion Plant, Paducah, Kentucky. In Waste Management 2006 Symposium. Tucson: WM Symposia, Inc.

Cross, B, Rogoff, E, Fricke, L (2005). Data Visualization Tools for Litigation - Practical Uses and Ethical Considerations. Proceedings of the 2005 NGWA Ground Water and Environmental Law Conference, Baltimore, MD, 1-14

Dominguez-Acosta, M, Granados-Olivas, A, Hibbs, B, Eastoe, C, Hawley, J (2004). Computer Based Three-Dimensional Modeling of Hydrogeologic units in the Transboundary Ciudad Juárez-Paso del Norte region. Second International Symposium on Transboundary Water Management Proceedings. Tucson, AZ 
Glynn, P, Jacobsen, L, Phelps, G, Bawden, G, Grauch, V, Orndorff, R, Winston, R, Fienen, M, Cross, V, Bratton, J (2011). 3D/4D Modeling, Visualization and Information Frameworks: Current US Geological Survey Practice and Needs. In Three-dimensional Geologic Mapping Workshop, Minneapolis, MN, 33-39

Gould, J, \& Lewis, C (1985). Designing for Usability: Key Principles and What Designers Think. Comm of the ACM, 28(3), 300-311.

Lai, JS, Chang, WY, Chan, YC, Kang, SC, \& Tan, YC (2011). Development of a 3D virtual environment for improving public participation: Case study-The Yuansantze Flood Diversion Works Project. Advanced Engineering Informatics, 25(2), 208-223.

Lemke, J, Driller, M, \& Wilson, D (2011). Web-based Real-time Monitoring at Perris Dam Using In-place Inclinometers and Piezometers with an Automatic Notification System. In 21st Century Dam Design - Advances and Adaptations, 31st Annual USSD Conference (pp. 1527-1540). San Diego, CA: United States Society on Dams.

Maccabiani, J, \& Knoeff, JG (2008). An online tool for real-time analysis and management of flood risks of diked areas. In 4 th Int. Symp. Flood Defence (pp. 1-8). Toronto, Canada: International Flood Initiative.

Pantea, MP, Hudson, MR, Grauch, VJS, \& Minor, SA (2011). Three-Dimensional Geologic Model of the Southeastern Española Basin, Santa Fe County, New Mexico. U.S. Geological Survey Scientific Investigations Report 2011-5025 (pp. 1-17). Denver, CO: USGS Geology and Environmental Change Science Center.

Qi, H, \& Altinakar, MS (2011). A GIS-based decision support system for integrated flood management under uncertainty with two dimensional numerical simulations. Environmental Modelling \& Software, 26(6), 817-821.

Rosen, JB, Arnold, MA, Bachus, RC, Schauer, D, \& Berrios, A (2011). GIS for Geotechnical Decision Making: Visualization of Cut-Off Wall Construction Data. In Geo-Frontiers 201: Advances in Geotechnical Engineering (pp. 2907-2916). ASCE.

Serre, D, Peyras, L, Tourment, R, \& Diab, Y (2008). Levee performance assessment methods integrated in a GIS to support planning maintenance actions. Journal of Infrastructure Systems, 14(3), 201-213.

Shaffner, P (2011). Geologic Data and Risk Assessment; Improving Geologic Thinking and Products. 21st Century Dam Design - Advances and Adaptations, 31st Annual USSD Conference, San Diego, CA, 545-569

Shumilov, S, \& Breunig, M (2000). Integration of 3D geoscientific visualization tools with help of a geo-database kerne. In Proceedings of the Sixth EC-GI \& GIS Workshop (pp. 66-76). Lyon, France: The Spatial Information Society-Shaping the Future.

Spencer, W D, Fritze, B, Greene, D C, and Haskins, T A (2010). The Use of Electronic Data Anaylsis and 3-D Modeling to Make Us Smarter. 30th Annual USSD Conference, Sacramento, CA, 653-681

United States Army Corps of Engineers. (2012). Improving Safety Monitoring for Embankment Dams. Pittsburgh, PA, USA: CMU

Wiegers, K (1999). First things first: prioritizing requirements. In Software Requirements (2nd ed.). Redmond, WA: Microsoft Press.

Xi-juan, J, Rui-sheng, J, \& Jing-bo, Z (2010). Multi-layer DEM modeling and application in stratum visualization based on IDL. In Computer Application and System Modeling (ICCASM), 2010 International Conference (pp. 150-154). Taiyuan, China: IEEE

Tulke, J, Tauscher, E, Theiler, M, and Thomas, R. Open IFC Toolbox. On-line: http:// www.ifctoolsproject.com. Accessed: 30 Aug 2013

\section{Submit your manuscript to a SpringerOpen ${ }^{\circ}$ journal and benefit from:}

- Convenient online submission

- Rigorous peer review

- Immediate publication on acceptance

- Open access: articles freely available online

- High visibility within the field

- Retaining the copyright to your article

Submit your next manuscript at $>$ springeropen.com 